\title{
AVALIAÇÃo DE GENÓTIPOS DE AVEIA BRANCA SOB ESTRESSE DE ÁCIDOS ORGÂNICOS $\left({ }^{1}\right)$
}

\author{
MAURICIO MARINI KOPP $\left({ }^{2 *}\right)$; VIVIANE KOPP DA LUZ $\left({ }^{3}\right)$; LUCIANO CARLOS DA MAIA $\left({ }^{3}\right)$; \\ ROGERIO OLIVEIRA DE SOUSA $\left({ }^{4}\right)$; FERNANDO IRAJÁ FÉLIX DE CARVALHO $\left({ }^{3}\right)$; \\ ANTONIO COSTA DE OLIVEIRA $\left({ }^{3}\right)$
}

\begin{abstract}
RESUMO
A ocorrência de condições anaeróbias nos solos hidromórficos, associada com a presença de matéria orgânica favorece o desenvolvimento de microrganismos anaeróbios que produzem substâncias fitotóxicas, principalmente ácidos orgânicos de cadeia curta. O objetivo do trabalho foi avaliar a resposta de 20 genótipos de aveia (Avena sativa L.) aos ácidos acético, propiônico e butírico. O trabalho foi executado em sistema de hidroponia com três doses $(0 ; 3$ e $6 \mathrm{mM})$ da mistura dos três ácidos na relação 6:3:1 respectivamente. O delineamento utilizado foi em blocos casualizados com três repetições em esquema fatorial. As variáveis mensuradas foram: comprimento de raízes (CR) e parte aérea (CPA), número de raízes (NR) e matéria seca de raízes (MSR) e parte aérea (MSPA). Foram procedidas análise de variância e ajustes de regressão. Os efeitos de interação entre doses x genótipos para as variáveis CR e MSR revelaram significância e as regressões estabelecidas para estas variáveis, revelaram dois genótipos com estabilidade de crescimento radicular (OR3 e FAPA-5) e três com estabilidade de acúmulo de matéria seca (OR-3, UFRGS-17 e UPF-15) frente ao estresse por ácidos orgânicos. A caracterização destes genótipos à ação fitotóxica dos ácidos orgânicos é importante fonte de recursos aos programas de melhoramento genético que visem obter genótipos com elevada capacidade produtiva, em solos de várzea do Sul do Brasil sob plantio direto ou cultivo mínimo.
\end{abstract}

Palavras-chave: Estresse abiótico, fitotoxidez, dissimilaridade genética, recursos genéticos.

\section{ABSTRACT \\ RESPONSES OF WHITE OAT GENOTYPES TO STRESSES OF ORGANIC ACIDS}

The association of anaerobic conditions with high organic matter content in hydromorphic soils favors the development of anaerobic microorganisms that produce phytotoxic substances, especially short chain organic acids. The objective of this investigation was to evaluate the response of 20 oat (Avena sativa L.) genotypes to the exposure of acetic, propionic and butyric acids in hydroponic system. Three doses $(0 ; 3$ and $6 \mathrm{mM}$ ) of a mixture of the three acids at a 6:3:1 ratio, respectively were tested. The experimental design was randomized blocks with three replications on a factorial scheme. Measured variables were root (CR) shoot (CPA) length, root number (NR), root (MSR) and shoot (MSPA) dry matter. Variance analyses and regression fitness were performed. The effects of the interaction between doses and genotypes were significant for the variables CR and MSR. The regression curves indicated two genotypes (OR-3 e FAPA-5) with stable root growth and three (OR-3, UFRGS-17 e UPF-15) with stable dry matter accumulation under organic acid stresses. The characterization of these genotypes regarding organic acid phytotoxic action is an important resource for breeding programs aiming at to develop high yielding cultivars for no-tillage or minimal tillage systems in hydromorphic soils of southern Brazil.

Key words: Abiotic stress, phytotoxicity, genetic dissimilarity, genetic resources.

( $\left.{ }^{1}\right)$ Recebido para publicação em 29 de janeiro de 2008 e aceito em 11 de fevereiro de 2009.

$\left(^{2}\right)$ Empresa Brasileira de Pesquisa Agropecuária - Embrapa Gado de Leite, Rua Eugênio do Nascimento, 610, Dom Bosco 36038-330 Juiz de Fora (MG). E-mail: kopp@cnpgl.embrapa.br $\left(^{*}\right)$ Autor correspondente.

$\left(^{3}\right)$ Centro de Genômica e Fitomelhormento, Universidade Federal de Pelotas, Campus Universitário, s/nº, Caixa Postal 354, 96010-900 Pelotas (RS). E-mail:vivikp05@yahoo.com.br; lucianoc.maia@gmail.com; carvalho@ufpel.tche.br; acostol@terra.com.br;

$\left({ }^{4}\right)$ Departamento de Solos, Universidade Federal de Pelotas, Caixa Postal 354, 96010-900 Pelotas (RS). E-mail: rosousa@ufpel.tche.br 


\section{INTRODUÇÃO}

A Região Sul do Brasil é constituída por uma área de 6,8 milhões de hectares com solos hidromórficos (várzea), representando $20 \%$ da área total do Estado do Rio Grande do Sul (PINTO et al., 2004). Nestes solos, a maioria das espécies cultivadas tem seu desenvolvimento e produção prejudicada devido à má drenagem natural, tornando o sistema arroz irrigado/pastagens nativas uma opção com poucas alternativas de sucessão ou rotação de culturas (Gomes e Magalhães, 2004). A aveia é uma incontestável planta que, incorporada ao solo, melhora as características físicas e químicas, podendo ser utilizada como forma de sucessão da lavoura de arroz irrigado, além do objetivo de manter o solo protegido no plantio direto.

A incorporação de resíduos culturais ao solo antes de novo plantio sofre potencialmente a desvantagem de que produtos fitotóxicos, oriundos do metabolismo do material orgânico incorporado, possam exercer efeitos negativos às plântulas (CAMARGo et al., 2001). Em solos de várzea, o alagamento provoca condições anaeróbias, onde o problema se agrava, devido à baixa eficiência metabólica microbiana na conversão do carbono presente, ocorrendo acumulação de compostos que afeta, de forma irreversível, a produtividade final das culturas (CAMARGO et al.,1995b; BRANCKER et al., 1996).

Dos numerosos compostos formados pelo metabolismo anaeróbico, destacam-se os ácidos orgânicos, especialmente os ácidos alifáticos de cadeia curta, como o acético, o propiônico e o butírico, que ocorrem usualmente na faixa de concentração de 0,1 a 14 mM (CAMARGo et al., 1993a) e relação de 6:3:1, respectivamente (BoHNEN et al., 2005). O tipo e a quantidade dos ácidos produzidos dependem basicamente da quantidade e qualidade do resíduo orgânico adicionado, da característica fermentativa da microbiota e das condições predominantes no solo (CAMARGo et al., 1995a; GLISSMANn e ConRAD, 2002).

Como a maior produção de ácidos ocorre na fase inicial do plantio, os efeitos descritos podem estar mais intimamente relacionados à fase de germinação de sementes. Na fase subseqüente de plântula, verifica-se número maior de referências a respeito do efeito negativo de ácidos orgânicos sobre o alongamento radicular da cultura do arroz (RAO e MikKelsen, 1977a,b; CAMARgo et al., 1993b; Kopp et al., 2007a) da cevada, do trigo, do milho, da aveia (KopP et al., 2007b) e do trevo (LYNCH et al., 1980). A maioria desses autores relatam, ainda, o efeito desses ácidos sobre o peso e altura das plântulas, bem como sobre a produção de matéria seca e absorção de nutrientes (SOUSA e BORTOLON, 2002; TONOUCHI, 2004).
De modo geral, esses efeitos podem ser o resultado de lesões causadas ao tecido meristemático da radícula (CHOU e PATRICK, 1976) ou de inibição à respiração (ROBSON e TAYLOR, 1974), o que deve resultar em inibição da divisão celular. Por outro lado, essas fitotoxinas são inibidoras de funções mitocondriais, incluindo o desacoplamento da fosforilação oxidativa, assim como do transporte de metabólitos e de enzimas glicolíticas solúveis no citossol e as ligadas a endomembranas, como as responsáveis pela síntese de polissacarídeos e a ATPase (ANGELES et al., 2005). Ácidos orgânicos causam o efluxo de íons inorgânicos e material orgânico para o meio externo, o que implica a danificação da integridade da plasmalema (CAMARGO et al., 2001).

Deve ser ressaltado, que no sistema de plantio direto prevê-se a manutenção de resíduos vegetais sob a superfície do solo, ocorrendo maior produção de ácidos orgânicos, que limitam o crescimento e a produtividade da aveia cultivada neste sistema em regiões de ocorrência de solos de várzea (CAMARGO et al., 2001). Assim, para que o cultivo da aveia seja uma alternativa economicamente viável nestes solos sob plantio direto, é necessário avaliar a adaptabilidade das cultivares existentes ao estresse por ácidos orgânicos.

Técnicas de avaliação de genótipos em ambientes controlados, com o uso de soluções nutritivas, têm sido amplamente utilizadas para caracterização de genótipos a diversos estresses. Enquanto a avaliação de genótipos em ambientes artificiais não leva em consideração as reais pressões do meio (Duncan e Baligar, 1990), a seleção em ensaios de campo reúne grande número de variáveis não controladas (WRIGHT, 1989). Correlações significativas entre parâmetros obtidos em testes de campo e em ambientes artificiais, são relatadas por BILINSKI e FOY (1987) em diversas gramíneas. Assim, uma maneira eficiente de avaliação de genótipos de aveia sob estresse por ácidos orgânicos pode ser realizada em sistema hidropônico sob condições controladas.

Os objetivos deste trabalho foram avaliar o desenvolvimento de genótipos de aveia submetidos à ação fitotóxica dos ácidos acético, propiônico e butírico, determinar a variável mais responsiva à fitotoxidez nas plântulas e identificar genótipos contrastantes para o caráter tolerância a ácidos orgânicos.

\section{MATERIAL E MÉTODOS}

O trabalho foi realizado no Laboratório de Dihaplóides e Hidroponia do Centro de Genômica e Fitomelhoramento (CGF) da Faculdade de Agronomia Eliseu Maciel da Universidade Federal de Pelotas 
(UFPel), localizado no município de Pelotas (RS). Foram utilizados 20 genótipos de aveia branca da coleção de trabalho do Banco de Germoplasma de Aveia do CGF/UFPel (Tabela 1), as quais foram submetidos a três doses de ácidos orgânicos.

Tabela 1. Resumo da análise de variância, médias e coeficiente de variação (CV) para as variáveis comprimento de raiz (CR) e de parte aérea (CPA), número de raízes (NR), matéria seca de raiz (MSR) e de parte aérea (MSPA) de 20 cultivares de aveia, estudadas em solução nutritiva com três concentrações dos ácidos acético, propiônico e butírico. Pelotas (RS), 2007

\begin{tabular}{lcccccc}
\hline \multirow{2}{*}{ F.V. } & \multirow{2}{*}{ G.L. } & \multicolumn{5}{c}{ Quadrados Médios } \\
\cline { 3 - 7 } & & CR & CPA & NR & MSR & MSPA \\
\hline Genótipo & 19 & $4,285^{*}$ & $14,026^{*}$ & $3,054^{*}$ & $0,890^{*}$ & 0,022 \\
Dose & 2 & $452,21^{*}$ & $130,51^{*}$ & $53,336^{*}$ & $72,141^{*}$ & $74,304^{*}$ \\
Interação & 38 & $5,403^{*}$ & 1,890 & 0,596 & $0,954^{*}$ & 0,003 \\
Resíduo & 118 & 0,102 & 3,341 & 0,493 & 0,114 & 0,759 \\
Média & - & 7,04 & 20,41 & 5,01 & 3,69 & 9,05 \\
\hline CV (\%) & - & 4,53 & 8,96 & 14,00 & 9,16 & 9,63
\end{tabular}

* Significativo a $5 \%$ de probabilidade.

O experimento foi desenvolvido em sistema hidropônico segundo metodologia descrita por KорP et al. (2007a), onde foram utilizados potes com capacidade de $5,5 \mathrm{~L}$, nos quais foi adaptada uma tela de náilon à tampa de cada pote, permitindo a sustentação das plântulas e o crescimento do sistema radicular para o meio de cultivo. Os potes permaneceram em tanque tipo "banho-maria" com temperatura de $25 \pm 1{ }^{\circ} \mathrm{C}$ e com aeração da solução nutritiva para suprimento de oxigênio, permitindo o desenvolvimento do sistema radicular e iluminação artificial controlada.

A concentração da solução nutritiva utilizada foi: Nitrato de cálcio - $\mathrm{Ca}\left(\mathrm{NO}_{3}\right)_{2} 4 \mathrm{mM}$, Sulfato de magnésio - $\mathrm{MgSO}_{4} 2 \mathrm{mM}$, Nitrato de potássio - $\mathrm{KNO}_{3}$ $4 \mathrm{mM}$, Sulfato de amônio - $(\mathrm{NH} 4)_{2} \mathrm{SO}_{4} \quad 0,435 \mathrm{mM}$, Potássio fosfato - $\mathrm{KH}_{2} \mathrm{PO}_{4} 0,5 \mathrm{mM}$, Acido bórico $\mathrm{H}_{3} \mathrm{BO}_{3} 10 \mu \mathrm{M}$, Molibdato de sódio - $\mathrm{NaMoO}_{4} 0,10 \mu \mathrm{M}$, Cloreto de sódio - $\mathrm{NaCl} 30 \mu \mathrm{M}$, Sulfato de zinco $\mathrm{ZnSO}_{4} 0,8 \mu \mathrm{M}$, Sulfato de cobre - $\mathrm{CuSO}_{4} 0,3 \mu \mathrm{M}$, Sulfato de manganês - $\mathrm{MnSO}_{4} 2 \mathrm{mM}$, Ferro EDTA - $\mathrm{Fe} \mathrm{SO}_{4}+$ Na $10 \mu \mathrm{M}$ (CAmargo e Oliveira, 1981).

Para constituição das parcelas experimentais, 120 sementes de cada cultivar foram desinfetadas com hipoclorito de sódio $10 \%$ e postas para germinar a $25 \pm 1{ }^{\circ} \mathrm{C}$ por 72 horas em papel filtro embebido em água. Dentre as sementes germinadas, foram selecionadas 90 com comprimento de raiz de aproximadamente $5 \mathrm{~mm}$ e uniformes para constituir o experimento.
As doses foram constituídas por três concentrações da mistura dos ácidos acético, propiônico e butírico na relação de 6:3:1 respectivamente. As concentrações utilizadas foram 0 (testemunha); 3 e $6 \mathrm{mM}$. O pH foi ajustado para 4,7 com $\mathrm{HCl} 1 \mathrm{~N}$ ou $\mathrm{NaOH} 1 \mathrm{~N}$, e monitorado diariamente.

O delineamento experimental utilizado foi o de blocos casualizados, com três repetições em esquema fatorial, sendo a unidade experimental constituída de dez sementes para cada repetição. Após realização do sorteio, as unidades experimentais foram alocadas nas telas de náilon adaptadas às tampas dos recipientes de solução hidropônica, contendo os tratamentos.

As plântulas permaneceram em solução nutritiva adicionada dos tratamentos por 14 dias. Após esse período elas foram retiradas da tela de náilon e avaliadas quanto as seguintes caracteres: comprimento de raízes (CR) e parte aérea (CPA) em $\mathrm{cm}$; número de raízes (NR); matéria seca de raízes (MSR) e de parte aérea (MSPA) em mg, pesadas após secagem até massa constante em estufa com circulação de ar a $60^{\circ} \mathrm{C}$.

Os dados relativos às variáveis mensuradas foram submetidos à análise de variância em um modelo fatorial, considerando dose e genótipo como fatores fixos. Os efeitos da interação entre estes fatores foram testados na análise de regressão linear, pela significância dos distintos graus do polinômio em função dos diferentes níveis do fator dose (quantitativo), sendo apresentados na forma de gráficos individuais para cada genótipo. Também foi executado teste de correlação simples de Spearman entre as variáveis mensuradas. Todas as análises foram realizadas com o software estatístico SAS (Statistical Analysis System, 2002).

\section{RESULTADOS E DISCUSSÃO}

Pelos resultados da análise de variância (Tabela 2), pelo teste F, verificam-se efeitos significativos, a $5 \%$ de significância, para dose, em todas as variáveis mensuradas, efeito de genótipo para as variáveis CR, CPA, NR e MSR e interação (dose $x$ genótipo), apenas para as variáveis CR e MSR. Por esses resultados, concluise que os genótipos permitem respostas diferenciais em relação ao efeito crescente das concentrações de ácidos orgânicos, devido a suas interações significativas para as variáveis $C R$ e MSR, o que implica a necessidade de decomposição de seus efeitos simples. 
Tabela 2. Resumo da análise de variância do modelo de regressão para as variáveis comprimento de raiz (CR) e matéria seca de raiz (MSR) de 20 cultivares de aveia, estudadas em solução nutritiva com três concentrações dos ácidos acético, propiônico e butírico. Pelotas (RS), 2007

\begin{tabular}{|c|c|c|c|c|}
\hline \multirow{4}{*}{ Genótipo } & \multicolumn{4}{|c|}{ Quadrados Médios } \\
\hline & \multicolumn{2}{|c|}{ CR } & \multicolumn{2}{|c|}{ MSR } \\
\hline & \multicolumn{2}{|c|}{ Grau do polinômio } & \multicolumn{2}{|c|}{ Grau do polinômio } \\
\hline & Linear & Quadrática & Linear & Quadrática \\
\hline OR 2 & $100,532^{*}$ & $2,28980^{*}$ & $7,21607^{*}$ & $1,15520^{*}$ \\
\hline OR 3 & 0,21282 & 0,00027 & 0,16667 & 0,00002 \\
\hline Albasul & $51,9793^{*}$ & 0,93389 & $10,6400^{*}$ & 0,01681 \\
\hline URS 20 & $106,429^{*}$ & $3,85494^{*}$ & $14,8523^{*}$ & $2,58402^{*}$ \\
\hline URS 21 & $15,1686^{*}$ & $2,58402^{*}$ & $3,31527^{*}$ & 0,65742 \\
\hline FAPA 4 & $114,931^{*}$ & $6,36056^{*}$ & $16,1048^{*}$ & $2,10125^{*}$ \\
\hline FAPA 5 & 0,39015 & 0,04401 & $8,56815^{*}$ & $0,76467^{*}$ \\
\hline UFRGS 7 & $28,1234^{*}$ & $3,65401^{*}$ & $6,72042^{*}$ & 0,61605 \\
\hline UFRGS 14 & $95,9200^{*}$ & $3,91067^{*}$ & $9,60135^{*}$ & 0,10734 \\
\hline UFRGS 15 & $66,5334^{*}$ & $1,84320^{*}$ & $8,14335^{*}$ & $0,75645^{*}$ \\
\hline UFRGS 17 & $32,4803^{*}$ & 0,22222 & 0,44827 & 0,00500 \\
\hline UFRGS 19 & $83,7761^{*}$ & $1,77976^{*}$ & $10,9891^{*}$ & $0,98000^{*}$ \\
\hline IAC 7 & $38,7604^{*}$ & 1,14005 & $10,8811^{*}$ & $0,80222^{*}$ \\
\hline CFT 1 & $40,3004^{*}$ & $1,45067^{*}$ & $4,54140^{*}$ & $1,11502^{*}$ \\
\hline UPF 7 & $69,4961^{*}$ & $6,94402^{*}$ & $13,0243^{*}$ & 0,14222 \\
\hline UPF 15 & $44,7174^{*}$ & 0,18402 & 0,23207 & 0,00500 \\
\hline UPF 16 & $41,2388^{*}$ & $3,15005^{*}$ & $11,1794^{*}$ & $4,53005^{*}$ \\
\hline UPF 17 & $72,2454^{*}$ & $6,99380^{*}$ & $9,10202^{*}$ & 0,07094 \\
\hline UPF 18 & $15,9414^{*}$ & $3,02580^{*}$ & $9,57607^{*}$ & $1,13502^{*}$ \\
\hline UPF 19 & $40,0934^{*}$ & 0,11681 & $7,48167^{*}$ & 0,19636 \\
\hline
\end{tabular}

* Significativo a $5 \%$ de probabilidade.

Essas respostas diferenciais em relação ao crescimento e à matéria seca de raízes (CR e MSR), diante das variações crescentes de concentrações de ácidos orgânicos ao qual estão submetidos os genótipos, indicam haver variabilidade genética quanto à insensibilidade a estes ácidos. $O$ fato de ter sido observado significância para a fonte de variação "genótipo", demonstra que existem também diferenças em relação à magnitude média dos valores destas variáveis para cada genótipo, independentemente da sua resposta. Assim, os genótipos descritos como tolerantes neste trabalho foram aqueles insensíveis à toxicidade por ácidos orgânicos, mesmo que suas médias não tenham sido elevadas. Esses genótipos foram assim escolhidos em virtude da maior possibilidade de possuírem alelos responsáveis pela manutenção da capacidade celular em manter o crescimento e acúmulo de matéria seca de raízes (CR e MSR), sob a presença do elemento tóxico.
A análise prosseguiu de modo que se verificasse a variação nas variáveis CR e MSR dos genótipos nos diferentes níveis de ácidos orgânicos empregados, utilizando análise de regressão, sendo então fixado o fator genótipo. Para as duas variáveis, com a aplicação das equações de regressão linear, foram obtidos os parâmetros até o segundo grau do polinômio, representados pelos valores de quadrado médio e a respectiva significância do polinômio (Tabela 2).

As equações de regressão com o devido ajuste do coeficiente de determinação $\left(R^{2}\right)$ estão apresentadas nas figuras 1 e 2 para as variáveis comprimento de raízes e matéria seca de raízes. As doses utilizadas para constituir o experimento foram previamente selecionadas com base em estudos com arroz de modo que as reduções relativas no desenvolvimento radicular fossem em torno de 50\% na dose mais elevada (RAO e Mikkelsen, 1977b; Camargo et al., 1993b; Sousa e Bortolon, 2002; Kopp et al., 2007a). 

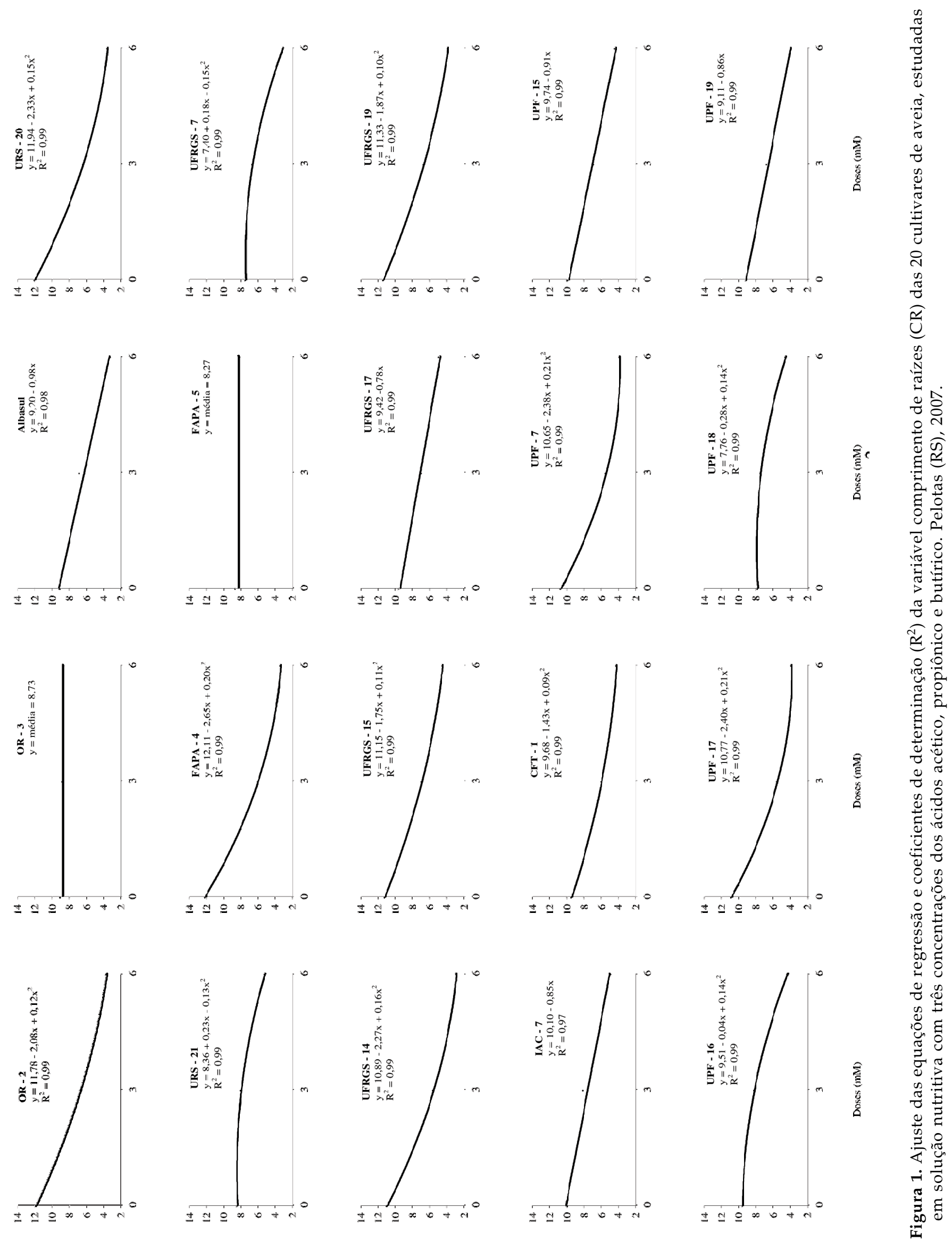

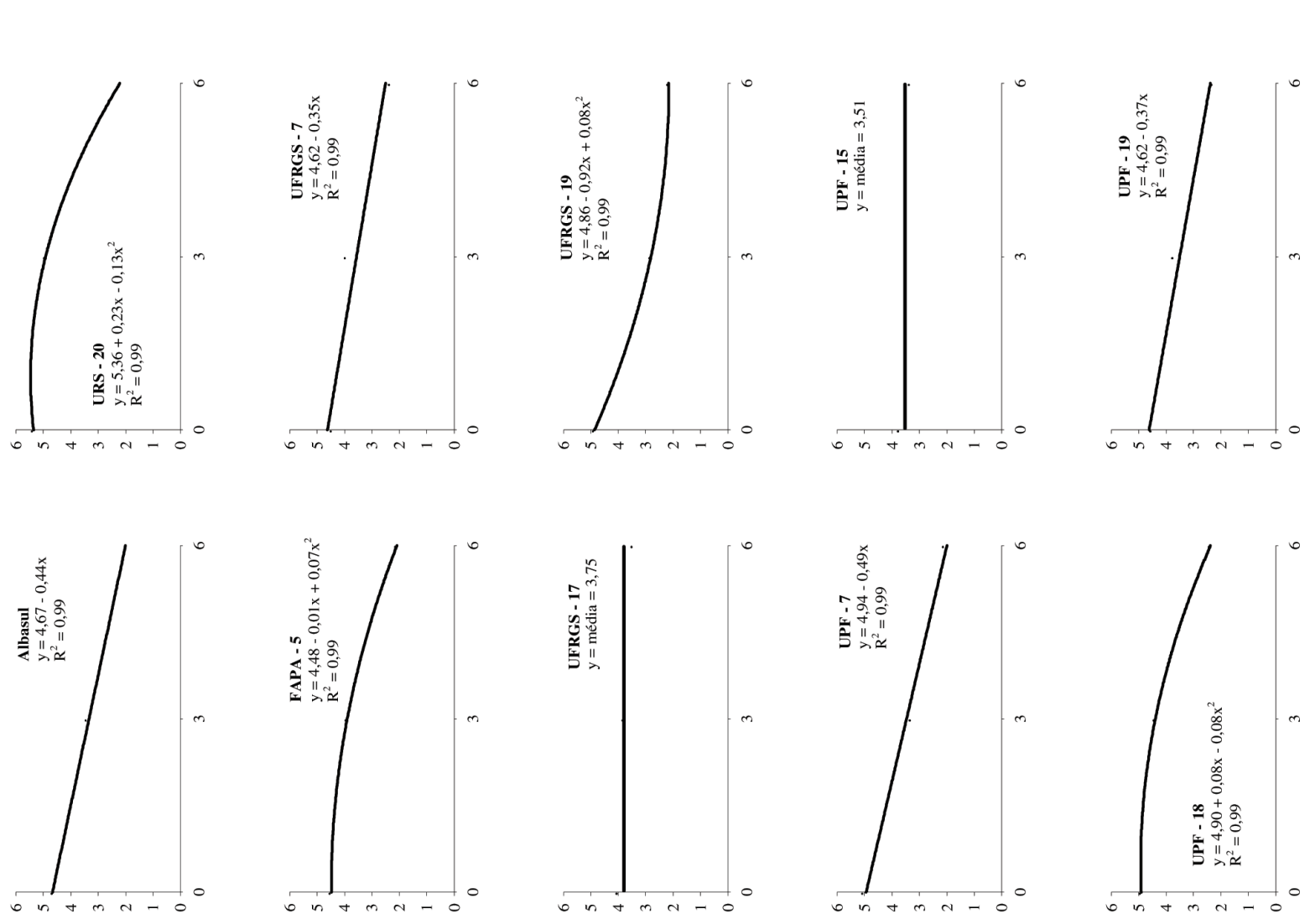

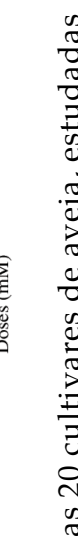
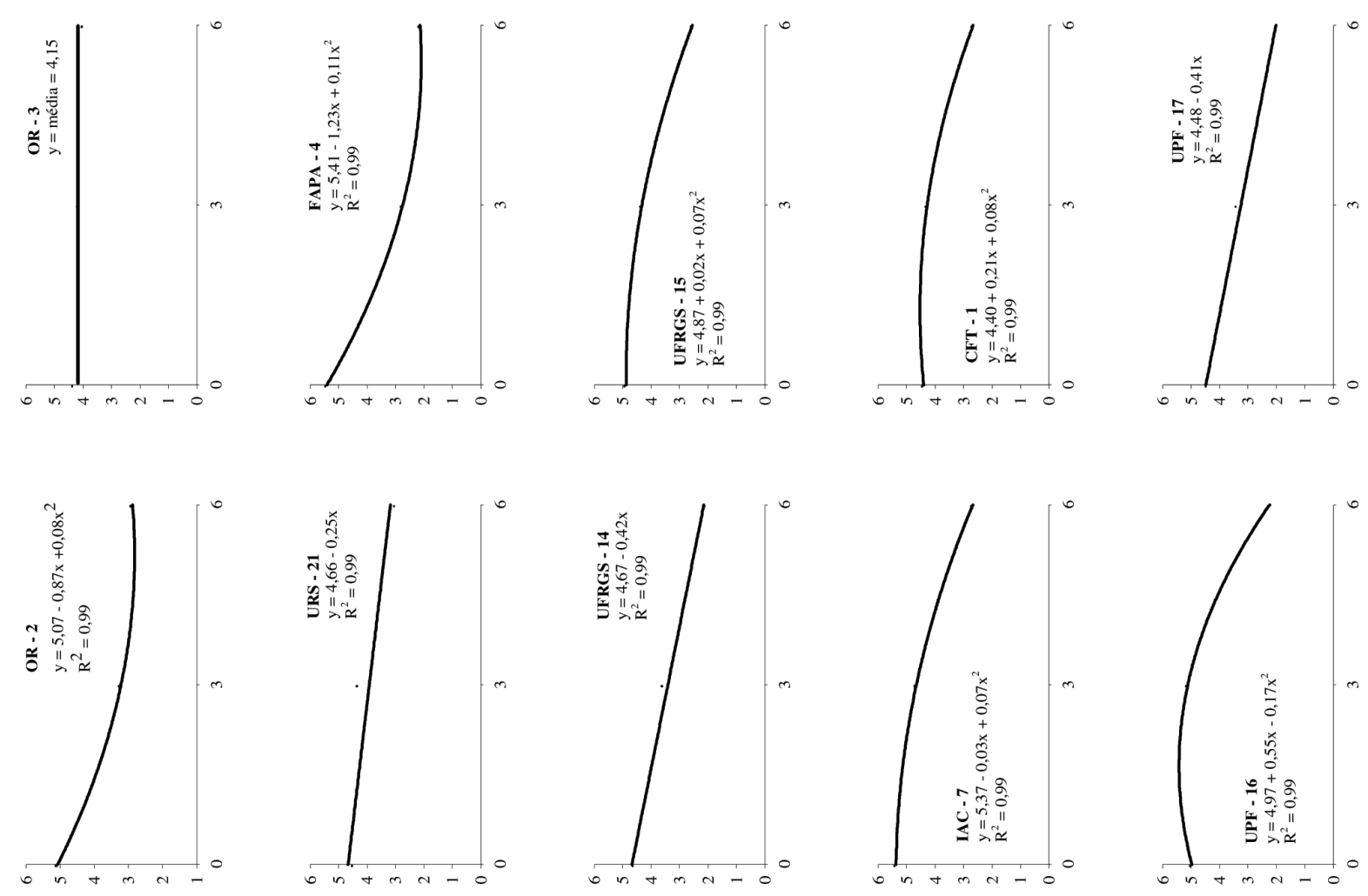

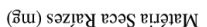

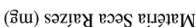

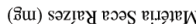

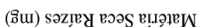

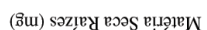

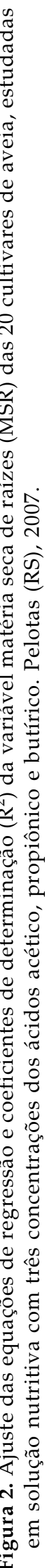


Pode ser observado que, para alguns genótipos, os resultados concordam com os trabalhos supracitados. No entanto, para a grande maioria dos genótipos avaliados as reduções foram superiores a $50 \%$ no crescimento de raízes, o que leva a crer que a cultura da aveia de maneira generalizada é mais suscetível à fitotoxidez por ácidos orgânicos que o arroz.

Ao analisar o comportamento dos genótipos frente ao crescimento de raízes (Figura 1), pode ser verificado que, para os genótipos OR-2, URS-20, FAPA-4, UFRGS-14, UFRGS-15, UFRGS-19, CFT-1, UPF-7 e UPF-17, há melhor ajuste de regressão quadrática, com maior decréscimo no comprimento de raízes em doses reduzidas dos ácidos e relativa estabilização do crescimento em doses superiores entre 3 e 6 mM. Já para os genótipos URS-21, UFRGS7, UPF-16 e UPF-18, houve ajuste de regressão quadrática, porém nestes casos, a maior redução no comprimento do sistema radicular foi observada em doses mais elevadas entre 3 e $6 \mathrm{mM}$; entre as doses de 0 e $3 \mathrm{mM}$, o desenvolvimento do comprimento de raízes praticamente não é afetado pela presença do elemento tóxico. Os genótipos com variação significativa com regressão linear foram Albasul, UFRGS-17, IAC-7, UPF-15 e UPF-19. Para esses casos, pode ser constatado que as reduções no crescimento de raízes foram constantes e significativas, para as faixas de doses utilizadas no trabalho. Estes resultados diferenciais de cada genótipo frente ao estresse também explicam as interações significativas entre doses e genótipos para a variável comprimento de raízes.

Para a variável matéria seca de raízes (Figura 2), o grupo de genótipos com regressões quadráticas e maior decréscimo de matéria seca em doses reduzidas (de 0 a $3 \mathrm{mM}$ ) foram OR-2, FAPA-4 e UFRGS-19, concordando parcialmente com os resultados do crescimento de raízes. Já os genótipos com regressão igualmente quadrática, porém com maior sensibilidade a doses mais elevadas (de 3 a 6 $\mathrm{mM}$ ), foram FAPA-5, UFRGS-15, IAC-7, CFT-1, UPF16 e UPF-18. Os genótipos Albasul, URS-21, UFRGS-7, UFRGS-14, UPF-7, UPF-17 e UPF-19 foram os que reduziram de forma significativa e linear o acúmulo de matéria seca. Assim como para a variável comprimento de raízes, esses resultados também explicam as interações significativas entre doses e genótipos para a variável matéria seca de raízes.

Como ainda não existe na literatura a descrição de níveis de redução para considerar um genótipo tolerante, ou mesmo ainda não descritos genótipos já classificados como tolerantes ou sensíveis para serem utilizados como testemunhas, foram considerados tolerantes os insensíveis às concentrações utilizadas, ou seja, aqueles cujas médias não alteraram significativamente com a elevação das doses utilizadas.

Os dados apresentados na figura 1, permitem concluir que para a variável comprimento de raízes, apenas para os genótipos OR-3 e FAPA-5 não houve variação significativa quando submetidos aos níveis de tratamento utilizados. Os dados revelam que até à concentração de $6 \mathrm{mM}$ da mistura dos ácidos utilizados, esses genótipos mantêm seu nível de crescimento radicular constante com médias de 8,73 e $8,27 \mathrm{~cm}$ respectivamente.

Para matéria seca de raízes, foi determinado outro grupo de genótipos com tolerância às concentrações de ácidos orgânicos. Para esta variável, os genótipos OR-3, UFRGS-17 e UPF-15 foram insensíveis à toxidez por ácidos orgânicos, com médias de 4,$15 ; 3,75$ e 3,51 cm respectivamente.

Cabe reinterar que os genótipos citados como tolerantes, não necessariamente possuem elevado potencial no desenvolvimento dessas variáveis, mas sim, elevada capacidade em manter seu patamar genético de crescimento e acúmulo de matéria seca. A acumulação desses ácidos no solo afeta diretamente algumas culturas, principalmente pela inibição da respiração, e degradação das membranas celulares com perda do conteúdo celular para o meio (ARMSTRONG e ARMSTRONG, 2001; ANGeles et al., 2005; JohnSON et al., 2006). Esses autores relatam ainda que plantas tolerantes devem possuir alelos que confiram maior capacidade de formação de membranas celulares que tolerem tais ácidos. Ao se realizar análise nas figuras 1 e 2 , pode ser constatado que, para ambas as variáveis, os genótipos tolerantes, não necessariamente, são também os genótipos com maior potencial em crescimento e acúmulo de matéria seca das raízes. Com exceção do genótipo OR-3, com elevada capacidade de acúmulo de matéria seca, são genótipos com capacidade limitada no desempenho destas variáveis, mas que possivelmente possuem alelos que mantém a viabilidade celular mediante a manutenção de suas membranas, garantindo a estabilidade de crescimento e massa seca das raízes ante a ação das doses de ácidos.

Este fato pode ser constatado também, analisando os valores de intercepto de cada genótipo, em que se percebe grande variabilidade genética para crescimento radicular na ausência de ácidos orgânicos na solução hidropônica (dose $0 \mathrm{mM}$ ). Os valores de crescimento radicular (Figura 1) na ausência de ácidos variam entre valores de 7,40 cm (genótipo UFRGS-7) até $12,11 \mathrm{~cm}$ (genótipo FAPA-4). 
No caso dos genótipos insensíveis, a presença dos ácidos para a variável crescimento de raizes (OR3 e FAPA-5), proporciona reduzido crescimento de raízes na ausência de ácidos orgânicos (dose $0 \mathrm{mM}$ ). Para a variável matéria seca de raízes (Figura 2), verificou-se menor variação proporcional, $\operatorname{com} 3,51 \mathrm{~cm}$ para o genótipo UPF-15 e 5,41 cm para o genótipo FAPA-4. O genótipo com menor matéria seca de raízes na ausência de ácidos orgânicos (UPF-15) é, também, um dos insensíveis ao efeito fitotóxico dos ácidos e o genótipo com maior acúmulo de matéria seca é também o que obteve o maior crescimento de raízes na dose de $0 \mathrm{mM}$ (FAPA-4).

Existem relatos de que a variável mais afetada pelo efeito dos ácidos orgânicos em arroz é o comprimento radicular, uma vez que o efeito fisiológico responsável pela toxicidade se caracteriza pelo rompimento das membranas do sistema radicular e extravasamento do conteúdo celular onde os ácidos estão em contato direto com os tecidos (JOHNSON et al., 2006). A seleção de genótipos para determinados caracteres pode ser feita indiretamente mediante análise de variáveis de mais fácil mensuração desde que haja correlações significativas (BENIN et al., 2003). Assim, se existir correlação significativa entre crescimento radicular ou matéria seca de raízes e outra variável com variação significativa, seria possível a identificação de genótipos tolerantes mediante a utilização de mais de uma variável simultaneamente sem prejuizo no resultado da análise.

Pela análise da correlação simples de Spearman (Tabela 3), verificou-se em todas as variáveis analisadas correlações significativas entre si. Na variável NR houve correlação negativa com todas as outras variáveis analisadas, pois esta variável foi a única com acréscimos no seu desempenho relativo frente ao estresse.

Tabela 3. Coeficientes de correlação de Spearman entre as variáveis comprimento de raiz $(\mathrm{CR})$ e parte aérea (CPA), número de raízes (NR) e matéria seca de raiz (MSR) e parte aérea (MSPA), de 20 cultivares de aveia, estudadas em solução nutritiva com três concentrações dos ácidos acético, propiônico e butírico. Pelotas (RS), 2007

\begin{tabular}{|c|c|c|c|c|c|}
\hline & CR & CPA & NR & MSR & MSPA \\
\hline CR & & $0,48^{*}$ & $-0,62^{*}$ & $0,87^{*}$ & $0,72^{*}$ \\
\hline CPA & & & $-0,24^{*}$ & $0,38^{*}$ & $0,68^{*}$ \\
\hline NR & & & & $-0,59^{*}$ & $-0,54^{*}$ \\
\hline MSR & & & & & $0,69^{*}$ \\
\hline MSPA & & & & & \\
\hline
\end{tabular}

As variáveis CR, CPA, MSR e MSPA tiveram correlações positivas e significativas entre si, demonstrando terem o mesmo desempenho generalizado, ou seja, reduções nos valores médios de uma variável são acompanhadas de reduções similares nas demais variáveis correlacionadas no grupo dos 20 genótipos estudados. Assim, além das variáveis CR e MSR, as demais podem ser utilizadas simultaneamente na análise, pois ocorre variação significativa para a fonte de variação "dose" e correlação significativa com as variáveis cuja interação (dose $\mathrm{x}$ genótipo) foi significativa. No entanto, não deve ser descartada a possibilidade de seleção baseada em avaliações independentes entre cada variável, pois podem ocorrer mecanismos genéticos diferenciais responsáveis pela tolerância de genótipos ante a estresses abióticos (YANG et al., 2000).

A quantidade de genótipos com insensibilidade ao efeito de ácidos orgânicos verificada neste trabalho, foi proporcionalmente inferior a obtida em outros estudos. A avaliação de 30 famílias mutantes de aveia revelou sete famílias $(23,33 \%)$ com tolerância dentro do grupo de genótipos estudado (Kopp et al., 2007b), enquanto a análise de 40 famílias mutantes de arroz, revelou 11 famílias $(27,5 \%)$ eficientes em tolerar ácido orgânico (Kopp et al., 2007c). Neste trabalho, foram obervados dois genótipos (OR-3 e FAPA-5) com elevada capacidade de crescimento radicular $(10 \%)$ e três genótipos (OR3, UFRGS-17 e UPF-15) com boa capacidade de acumular matéria seca $(15 \%)$ na presença destes elementos fitotóxicos. Este fato implica a possibilidade de que o pool gênico, atualmente utilizado na obtenção de cultivares de aveia branca no Brasil, pode não estar sendo eficiente em gerar constituições genéticas com presença de alelos responsáveis pela tolerância a ácidos orgânicos, conseqüentemente com reduzida capacidade de utilização em solos de várzea característicos do sul do Estado do Rio Grande do Sul. De certa forma, essa redução seria esperada uma vez que os programas de melhoramento de aveia branca têm hoje um foco em terras altas, o que diminuiria a pressão de seleção para este caráter.

Os resultados médios obtidos demonstram uma redução em torno de $55,42 \%$ no comprimento radicular e $46,29 \%$ na matéria seca de raízes, quando avaliados todos os genótipos na dose de $9 \mathrm{mM}$. Em estudo similar, porém trabalhando com doses de 0; 7 e $10 \mathrm{mM}$ e outro grupo de genótipos de aveia branca (mutantes), foram constatadas reduções no comprimento radicular de $52,4 \%$ e na matéria seca de raízes de $38,7 \%$ (Kopp et al., 2007b). Interpolando os valores do trabalho de Kopp et al. (2007b) e comparando com os resultados deste trabalho, pode-se constatar que as cultivares, de maneira geral, tiveram maior sensibilidade à ação 
tóxica dos ácidos orgânicos. Desse modo, parece haver maior frequência de alelos responsáveis pela manutenção da integridade celular na população mutante, oriunda da cultivar UFRGS 14, estudada por Kopp et al. (2007b), em relação ao grupo de cultivares utilizados neste trabalho. Embora a cultivar de origem da população mutante tenha sido sensível no presente trabalho, a indução de mutações foi eficiente em gerar novas constituições genéticas com maior tolerância. No entanto, futuros estudos genéticos planejados pelo Centro de Genômica e Fitomelhoramento da UFPel poderão comprovar de maneira mais efetiva esta tolerância.

Armstrong e Armstrong (2001), estudando o efeito dos ácidos orgânicos em arroz, relataram que plantas tolerantes devem possuir genes que confiram maior capacidade de formação de membranas celulares que tolerem tais ácidos. Em geral, os genótipos de maior rusticidade são tolerantes a muitos tipos de estresse bióticos e abióticos, em virtude principalmente de sua capacidade diferencial na constituição e formação do sistema membranário (Hincha e Hagemann, 2004). Os genótipos utilizados neste estudo são cultivares melhoradas, oriundas, normalmente, de cruzamentos entre genótipos de elevada rusticidade, no entanto, ao longo dos diversos ciclos de hibridação/seleção, perderam suas características rústicas tornando-se altamente adaptadas aos ambientes nos quais houve seleção.

Os efeitos dos ácidos orgânicos são dependentes do $\mathrm{pH}$ da solução onde ocorre o desenvolvimento radicular cujos níveis reduzidos de pH aumentam a toxidez de cada ácido orgânico, pois aumentam a forma não dissociada destes elementos (Kopp et al., 2007c). Além disso, quanto maior o tamanho da cadeia de carbonos do ácido, maior é sua fitotoxidez (Rao e MikKelsen, 1977a; Angeles et al., 2005). Kopp et al. (2007a) demonstraram que uma concentração de $10 \mathrm{mM}$ de cada ácido reduziu o crescimento radicular de arroz em torno de $44 \%$ com ácido acético, $70 \%$ propiônico e $77 \%$ para o butírico, demonstrando maior fitotoxidade do ácido butírico. Em função dos fatores ambientais, cabe reiterar que, apesar da elevada correlação verificada entre experimentos em ambiente controlado e em campo (BILINSKI e Foy, 1987), os resultados deste trabalho devem ser confirmados em condições naturais em campo sem ambiente controlado e áreas onde ocorram estresses com diferentes níveis de $\mathrm{pH}$ e proporções de ácidos orgânicos.

Assim, os genótipos descritos neste estudo como insensíveis à presença de ácidos orgânicos podem ser de grande valia na obtenção de populações para estudos genéticos de mapeamento ou de expressão gênica. Também pode ser ressaltada sua utilização por programas de melhoramento genético que visem obter genótipos com elevada capacidade produtiva na sucessão de cultura com arroz irrigado em solos de várzea do Sul do Brasil sob plantio direto ou cultivo mínimo. Esse sistema reduziria significativamente os custos de produção e danos ambientais advindos do sistema de semeadura convencional, bem como aumentaria consideravelmente a produtividade final das culturas.

\section{CONCLUSÕES}

1. Doses de até $9 \mathrm{mM}$ da mistura dos ácidos acético, propiônico e butírico na relação de 6:3:1, respectivamente, causaram reduções eficientes para estudos de variabilidade genética em aveia.

2. Foi identificada variabilidade genética para crescimento e acúmulo de matéria seca de raízes no grupo de genótipos de aveia quando submetidos ao efeito fitotóxico de ácidos orgânicos.

3. As cultivares OR-3 e FAPA-5 tiveram estabilidade no crescimento de raízes e as cultivares OR-3, UFRGS-17 e UPF-15, estabilidade no acúmulo de matéria seca de raízes quando submetidas a níveis crescentes de ácidos orgânicos.

\section{REFERÊNCIAS}

ANGELES, O.R.; JOHNSON,S.E.; BURESH, R.J. Soil solution sampling for organic acids in rice paddy soils. Soil Society American Journal, Madison, v.70, p.48-70, 2005.

ARMSTRONG, J.; ARMSTRONG, W. Rice and Phragmites: effects of organic acids on growth, root permeability, and radial oxygen loss to the rhizosphere. American Journal of Botany, Columbus, v.88, n.8, p.1359-1370, 2001.

BENIN, G.; CARVALHO, F.I.F.; OLIVEIRA, A.C.; ASSMANN, I.C.; FLOSS, E.L.; LORENCETTI, C.; MARCHIORO, V.S.; SILVA, J.G. Implicações do ambiente sobre o rendimento e suas influências sobre estimativas de parâmetros genéticos. Revista Brasileira de Agrociência, Pelotas, v.9, n.3, p.207$214,2003$.

BILINSKI, J.J.; FOY, C.D. Differential tolerances of oat cultivars to aluminum in nutrient solutions and in acid soils of plant. Journal of Plant Nutrition, New York, v.10, n.2, p.129-141, 1987.

BOHNEN, H.; SILVA, L.S.; MACEDO, V.R.M.; MARCOLIN, E. Ácidos orgânicos na solução de um gleissolo sob diferentes sistemas de cultivo com arroz irrigado. Revista Brasileira de Ciência do Solo, Viçosa, v.29, n.3, p.475-480, 2005.

BRANCKER, A.; CAMARGO, F.A.O.; SANTOS, G.A. Occurrence of physiological disease in flooded rice fields. Ciência Rural, Santa Maria, v.26, n.1, p.149-151, 1996. 
CAMARGO, C.E.O.; OLIVEIRA, O.F. Tolerância de cultivares de trigo a diferentes níveis de alumínio em solução nutritiva e no solo. Bragantia, Campinas, v.49, n.1, p.21-23, 1981.

CAMARGO, F.A.; ZONTA, E.; SANTOS, G. de A.; ROSSIELO, R.O.P. Aspectos fisiológicos e caracterização de toxidez a ácidos orgânicos voláteis em plantas. Ciência Rural, Santa Maria, v.31, n.3, p.523-529, 2001.

CAMARGO, F.A.O.; SANTOS, G.A.; ROSSIELLO, R.O.P. Acúmulo de nutrientes pelo arroz influenciado pela incorporação de palha em gleissolo. Revista Brasileira de Ciência do Solo, Viçosa, v.19, n.2, p.243-247, 1995b.

CAMARGO, F.A.O.; SANTOS, G.A.; ROSSIELLO, R.O.P. Efeito dos ácidos acético e butírico sobre o crescimento de plântulas de arroz. Pesquisa Agropecuária Brasileira, Brasilia, v.28, n.9, p.1011-1018, 1993b.

CAMARGO, F.A.O.; SANTOS, G.A.; ROSSIELLO, R.O.P. Incorporação de palha de arroz em um gleissolo e efeitos no rendimento da cultura do arroz irrigado. Pesquisa Agropecuária Brasileira, Brasilia, v.30, n.7, p.983-987, 1995a.

CAMARGO, F.A.O.; SANTOS, G.A.; ROSSIELLO, R.O.P. Produção de ácidos orgânicos voláteis pela planta de arroz sob condições anaeróbicas. Revista Brasileira de Ciência do Solo, Viçosa, v.17, n.3, p.337-342, 1993a.

CHOU, C.H.; PATRICK, Z.A. Identification and phytotoxic activity of compounds produced during composition of corn and rye residues in soil. Journal of Chemistry and Ecology, Oxon, v.2, n.3, p.369-383, 1976.

DUNCAN, R.R.; BALIGAR, V.C. Genetics, breeding, and physiological mechanisms of nutrient uptake and use efficiency: an overview. In: BALIGAR, V.C.; DUNCAN, R.R. (Ed.). Crops as Enhancers of Nutrient Use. San Diego: Academic Press, 1990. p.3-35.

GLISSMANN, K.; CONRAD, R. Saccharolytic activity and its role as a limiting step in methane formation during the anaerobic degradation of rice straw in rice paddy soil. Biology and Fertility of Soils, New York, v.35, p.62-67, 2002.

GOMES, A.S.; MAGALHÃES JR., A.M. Arroz irrigado no sul do Brasil. Brasília: Embrapa-Informação Tecnológica. 2004. 899 p.

HINCHA, D.K.; HAGEMANN, M. Stabilization of model membranes during drying by compatible solutes involved in the stress tolerance of plants and microorganisms. Biochemical Journal, London, v.383, n.2, p.277-283, 2004.

JOHNSON, S.E.; ANGELES, O.R.; BRAR, D.S.; BURESH, R.J. Faster anaerobic decomposition of a brittle straw rice mutant: implications for residue management. Soil Biology \& Biochemistry, Oxford, v.38, n.7, p.1880-1892, 2006.

KOPP, M.M.; COIMBRA, J.L.M.; LUZ, V.K.; SOUSA, R.O.; CARVALHO, F.I.F.; OLIVEIRA, A.C. Organic acid tolerance in $\mathrm{M}_{3}$ families of oat mutants. Crop Breeding and Applied Biotechnology, Viçosa, v.7, n.1, p.59-66, 2007b.
KOPP, M.M.; LUZ, V.K.; COIMBRA, J.L.M.; SOUSA, R.O.; CARVALHO, F.I.F.; OLIVEIRA, A.C. Níveis críticos dos ácidos acético, propiônico e butírico para estudos de toxicidade em arroz em solução nutritiva. Acta Botanica Brasílica, São Paulo, v.21, n.1, p.147-154, 2007a.

KOPP, M.M.; LUZ, V.K.; SILVA, V.N.; COIMBRA, J.L.M.; MAIA, L.C.; CARVALHO, F.I.F.; OLIVEIRA, A.C. Efeito do $\mathrm{pH}$ da solução nutritiva na fitotoxidez causada por ácidos orgânicos em arroz. Magistra, Cruz das Almas, v.19, n.1, p.40-46, 2007c.

LYNCH, J.M.; GUNN, K.B.; PANTING, L.M. On the concentration of acetic acid in straw and soil. Plant and Soil, The Hague, v.56, n.1, p.93-98, 1980.

PINTO, L.F.E.; LAUS, J.A.; PAULETTO, E.A. Solos de várzea no sul do Brasil. In: GOMES, A. S.; MAGALHÃES JUNIOR, A.M. Arroz irrigado no sul do Brasil. Brasília, DF: Embrapa Informação Tecnológica. 2004. p.75-95.

RAO, D.N.; MIKKELSEN, D.S. Effect of acetic, propionic, and butyric acids on rice seedlings growth. and nutrition. Plant and Soil, The Hague, v.47, n.6, p.323-334, 1977b.

RAO, D.N.; MIKKELSEN, D.S. Effect of acetic, propionic, and butyric acids on young rice seedlings growth. Agronomy Journal, Madison, v.69, n.6, p.923-928, 1977a.

ROBSON, T.W.; TAYLOR, A.B. Effect of acetic acid on the respiration of parts of oat seedlings. American Journal of Botany, Columbus, v.28, n.10, p.135, 1974.

SOUSA, R.O.; BORTOLON, L. Crescimento radicular e da parte aérea do arroz (Oryza sativa L.) e absorção de nutrientes em solução nutritiva com diferentes concentrações de ácido acético. Revista Brasileira de Agrociência, Pelotas, v.8, n.3, p.231-235, 2002.

STATISTICAL ANALYSIS SYSTEM. SAS: Statistical Analysis System - Getting Started with the SASÒ Learning Edition. Cary, North Carolina: SAS Institute. 2002. 86p.

TONOUCHI, A. Anaerobic 2-propanol degradation in anoxic paddy soil and the possible role of methanogens in its degradation. Current Opinion in Microbiology, London, v.49, p.75-78, 2004.

WRIGHT, R.J. Soil aluminum toxicity and plant growth. Communications in Soil Science and Plant Analysis, New York, v.20, n.15, p.1479-1497, 1989.

YANG, G.; YOUNG-YELL, M.; JI-YOUNG, M. Identification of rice varieties with high tolerance or sensitivity to lead and characterization of the mechanism of tolerance. Plant Physiology, Rockville, v.124, p.1019-1026, 2000. 